\title{
Effects of vasodilator and esmolol-induced hemodynamic stability on early post-operative cognitive dysfunction in elderly patients: a randomized trial.
}

\author{
Sheng-Hui Sun ${ }^{1}$, Lin Yang ${ }^{2}$, De-Feng Sun 3 , Yue Wu ${ }^{3}$, Jun $\mathrm{Han}^{3}$, Ruo-Chuan Liu³ Li-Jie Wang ${ }^{3}$
}

1. Class twelve Grade two, The Middle School Attached to Liaoning Normal University, Dalian, Liaoning, China

2. Department of Nerve Electroneurophysiology, The First Affiliated Hospital of Dalian Medical University, Dalian, Liaoning, China

3. Department of Anesthesiology, The First Affiliated Hospital of Dalian Medical University, Dalian, Liaoning, China

\begin{abstract}
Objective: To investigate the effect of continuous intravenous injection of nicardipine and/or nitroglycerin with or without esmolol on the occurrence of early post-operative cognitive dysfunction (POCD) in elderly patients.

Methods: Elderly patients $(n=340)$ who underwent radiofrequency ablation for atrial fibrillation were randomized into five groups: A, nicardipine; B nicardipine+esmolol; C, (nitroglycerin) group; D nitroglycerin+esmolol; E (control) groups. The hemodynamic parameters were recorded, and Mini Mental State Examination was used to assess cognitive function.

Results: At $30 \mathrm{~min}$ and 60 minutes after anesthesia and at the conclusion of surgery, the rate pressure product value was

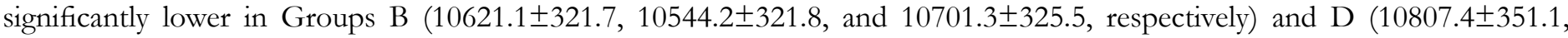

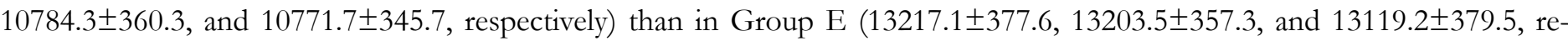
spectively). The heart rate was significantly higher in Groups A $(104.1 \pm 10.3,104.9 \pm 11.1$, and 103.9 \pm 11.8 , respectively) and C $(103.7 \pm 11.3,105.5 \pm 10.5$, and 107.7 \pm 11.7 , respectively) than in Group $\mathrm{E}(89.3 \pm 12.0,88.5 \pm 11.5$, and $85.5 \pm 11.6$, respectively). The incidence of POCD was significantly lower in Groups A and B than in Groups C, D, and E. Univariate regression analysis showed that regimens in Groups A, B, and E and doses of propofol and fentanyl were risk factors for POCD. Multivariate logistic regression analysis revealed significant associations between the incidence of POCD and interventions in Groups A and B.

Conclusion: Maintenance of stable intraoperative hemodynamics using nicardipine and nitroglycerin or their combinations with esmolol, especially nicardipine with esmolol, reduced the incidence of POCD in the elderly with potential cardiovascular diseases.
\end{abstract}

Keywords: Nicardipine, esmolol, nitroglycerin, hemodynamics, post-operative cognitive dysfunction.

DOI: http://dx.doi.org/10.4314/ahs.v16i4.23

Cite as: Sun S-H, Yang L, Sun D-F, Wu Y, Han J, Liu R-C, Wang L-J. Effects of vasodilator-and esmololinduced hemodynamic stability on early postoperative cognitive dysfunction in elderly patients: a randomized trial. Afri Health Sci2016;16(4): 1056-1066. bttp:/ / dx.doi. org/10.4314/abs.v16i4.23

\section{Introduction}

Post-operative cognitive dysfunction (POCD) is a shortterm decline of cognitive function that has been increasingly recognized as a central nervous system complication occurring after major or emergency surgery, especially in
Corresponding author:
De-Feng Sun,
Department of Anesthesiology,
The First Affiliated Hospital of
Dalian Medical University Dalian,
Liaoning, 116011, China;
Fax: 0086411-87614934,
Tel:008618098876191
Email: sundefengyl@163.com

elderly patients ${ }^{1-4}$. This disorder usually manifests as a decline in memory, attention, language ability and/or social interaction ${ }^{2,4,5}$, and severe POCD can lead to changes in a patient's personality and social behavior ${ }^{3,5,6}$. Although the causes of POCD remain unclear, multiple diverse contributing factors have been suggested, including older age, which has been identified as an independent risk factor for developing POCD ${ }^{3,7,8}$. As such, an increase in POCD incidence is expected to parallel societal increases in the elderly patient population, increasing the importance of identifying its etiology so that efforts may be made to reduce incidence rates and/or improve the quality of life for afflicted individuals.

Brain activation reduces the balance between cerebral consumption of oxygen and carbohydrate in terms of 
the cerebral oxygen-carbohydrate index $(\mathrm{OCI})^{9}$, which is a ratio determined by the cerebral uptake of oxygen compared with that of carbohydrate ${ }^{10-13}$. Surgery and anesthesia can cause a strong stress response, leading to the secretion of many hormones such as adrenaline, noradrenaline, and cortisol ${ }^{14,15}$. An increase in the sympathetic nervous activity increases the $\mathrm{OCI}^{16}$. Imbalance in cerebral metabolism during anesthesia leads to the development of clinical symptoms, including postoperative fatigue and cognitive dysfunction ${ }^{9,17}$. Early POCD, which occurs within a week of the triggering event, is associated with the induction of anesthesia ${ }^{18}$. Li et al. ${ }^{19}$ found that treatment with calcium channel antagonists may protect against neuronal damage, improve cognitive function, and delay cognitive dysfunction. Calcium channel antagonists have been found to influence cerebral metabolism, and beta-receptor blockers have been shown to have no effect on $\mathrm{OCI}^{16,20,21}$. Several studies have shown that the uptake of lactate and glucose reduces $\mathrm{OCI}^{22,23}$. It remains to be determined whether calcium channel blockers and beta-receptor blockers affect early POCD in elderly patients after surgery.

Nicardipine, a second-generation dihydropyridine calcium channel blocker, is known to have a rapid onset after intravenous injection. It selectively relaxes the smooth muscle of the coronary artery and systemic arterioles, producing vasodilation and thus decreasing cardiac afterload, thereby lowering blood pressure ${ }^{24}$. Nitroglycerin, another antihypertensive drug, primarily dilates veins, causing blood accumulation in the peripheral vasculature, with less blood ultimately returning to the ventricles, thereby reducing cardiac preload. It can also dilate the peripheral arteries to reduce cardiac afterload ${ }^{25}$. However, both drugs can induce tachycardia and increase myocardial oxygen consumption. Esmolol is an ultrashort-acting $\beta$-adrenoceptor blocker, which can reduce the heart rate, prolong coronary perfusion, and increase subendocardial blood flow ${ }^{26-30}$. Vasoactive therapeutic agents such as combinations of esmolol with nicardipine or nitroglycerin are often used to maintain hemodynamic stability and associated with a decrease in stress responses in the perioperative period ${ }^{24-30}$. However, it remains unclear whether the combined use of esmolol with either nicardipine or nitroglycerin to maintain hemodynamic stability affects the incidence of POCD in elderly patients after surgery.
The purpose of this study was to investigate the effect of continuous intravenous injection of nicardipine, nitroglycerin, and their pairwise combination with esmolol to maintain hemodynamic stability on early POCD in elderly patients undergoing radio-frequency ablation of atrial fibrillation under intravenous anesthesia, and to identify an improved vasoactive drug regimen that can stably control intra-operative hemodynamics with reduced incidence of POCD.

\section{Materials and methods \\ Patients}

All ongoing and related trials for this drug/intervention were registered. This clinical trial was first registered on 18/10/2011 (registration number:KY2011-40 ) with the Ethics Committee of the First Hospital of Dalian Medical University prior to patient recruitment, and a supplementary registration was made with the Chinese Ethics Committee of Registering Clinical Trials on 27/12/2013 ( registration number: ChiCTR-TRC-13004044). All patients or their relatives provided written informed consent prior to inclusion in the study.

The study included 340 elderly patients (156 males and 184 females) with intubation, who underwent elective radio-frequency ablation of atrial fibrillation under intravenous anesthesia from January 1, 2012 to September 30, 2014. The average age of patients was $82.0 \pm 7.0$ years (range, 75-89 years). Mean body weight was $73.5 \pm 13.5$ $\mathrm{kg}$ (range, 60-87 kg). Inclusion criteria were as follows: 1) American Society of Anesthesiology (ASA) II or III; 2) Mini-Mental State Examination (MMSE) score of $>$ 23 ; 3) greater than six years of education; 4) no history of neurological diseases or hyperthyroidism; 5) normal liver and kidney function; 6) no impairment of vision and hearing; and 7) no administration of sedative, antidepressant or analgesic drugs. Through the use of a computer-generated random number table to reduce the possibility of subjective sampling, patients were immediately assigned into five groups according to the drugs administered in the operation room: nicardipine group (Group A, $\mathrm{n}=68)$, nicardipine + esmolol group (Group B, $n=68)$, nitroglycerin group (Group C, $\mathrm{n}=68$, nitroglycerin + esmolol group (Group D, n=68), and control group (Group $E, n=68)$. All patients and staff members were blinded to group allocation. 


\section{Anesthesia procedure}

All patients participated in pre-operative fasting for $8 \mathrm{~h}$ prior to surgery, with only light liquid allowed in the last $2 \mathrm{~h}$ prior. No pre-operative drugs were administered. The patients' electrocardiography (ECG), heart rate (HR), blood pressure (BP), and blood oxygen saturation $\left(\mathrm{SpO}_{2}\right)$ were routinely monitored in the operating room. General anesthesia was induced through an intravenous injection combination of fentanyl $(2 \mathrm{mg} / \mathrm{kg}$; Yichang Humanwell Pharmaceutical, Yichang, China: Lot. No. 2110606), propofol (1.5 mg/kg; Xian Libang Pharmaceutical, Xian, China: Lot. No. 1203071) and cisatracurium $(0.2 \mathrm{mg} / \mathrm{kg}$; JiansuHengRui Medicine, Lianyungang, China: Lot. No. 12021917). Patients were then intubated under direct observation, and connected to a mechanical ventilator attached to an anesthesia machine. An additional bolus of fentanyl $(1 \mu \mathrm{g} / \mathrm{kg})$ was intravenously injected $5 \mathrm{~min}$ before the skin was incised. Anesthesia was maintained with continuous infusion of propofol $(2-3 \mathrm{mg} / \mathrm{kg} / \mathrm{h})$, cisatracurium $(2 \mu \mathrm{g} / \mathrm{kg} / \mathrm{min})$, and fentanyl $(0.5 \mu \mathrm{g} / \mathrm{kg} / \mathrm{h})$. Five minutes after the initial intravenous injection of anesthetics, patients received continuous intravenous infusion of : nicardipine $(3-\mathrm{g} / \mathrm{kg} / \mathrm{min})$ - group A; nicardipine (3-g/ $\mathrm{kg} / \mathrm{min})+$ esmolol (30-g/ $\mathrm{kg} / \mathrm{min}) —$ group B; nitroglycerin $(3-\mathrm{g} / \mathrm{kg} / \mathrm{min})$ - group C; nitroglycerin $(3-\mathrm{g} / \mathrm{kg} / \mathrm{min})$ + esmolol (30-g/kg/min) - group D; and an equal volume of normal saline-group E. During surgery, the intravenous infusion rate of propofol, fentangyl and liquids or antihypertensive drugs was adjusted based on each patient's BP and bispectral index (BIS). For the patients in Group E, anesthetic drugs were used to control blood pressure if the BIS was below 60 . Blood pressure was controlled to $20 \%$ of baseline (10 min before the initiation of anesthesia), and the BIS value was maintained between 50-60. Also during surgery, sodium lactate Ringer's solution and 6\% hydroxyethyl starch (130/0.4 in $0.9 \%$ sodium chloride; Voluven; Fresenius KabiNorge A.S., Halden, Norway) were administered intravenously at an infusion rate of $5-10 \mathrm{~mL} / \mathrm{kg} / \mathrm{h}$. At the end of operation, delivery of all drugs was immediately and completely stopped.When BIS values reached 80 , and patients were considered recovered from anesthesia and the tracheal tube was subsequently removed.

Patients were transitioned from the operating room when the Steward recovery score was $\geq 4$. The Steward recov- ery score was assessed as follows: Consciousness: 0 for no consciousness, 1 for responding to stimuli, and 2 for full consciousness; airway: 0 for airway requiring maintenance, 1 for maintaining good airway, and 2 for coughing on command; and movement: 0 for no movement, 1 for no purposeful movement, and 2 for purposeful movement.

\section{Anesthesia monitoring}

The patients' electrocardiography (ECG), heart rate (HR), blood pressure (BP), and blood oxygen saturation $\left(\mathrm{SpO}_{2}\right)$ were routinely monitored in the operating room. The radial artery and jugular vein were catheterized in order to monitor mean arterial pressure (MAP), HR, cardiac output (CO), stroke volume (SV) and central venous pressure (CVP); monitoring was carried out using a Mindray Beneview T8 monitor (Shenzhen Mindray Bio-Medical Electronics, China) and a Flotrac Vigileo monitoring system (Edwards Lifesciences LLC, USA.). BIS was monitored using a HXD-1 multifunctional electroencephalogram monitor (Heilongjiang Huaxiang Technical Developing Company, Harbin, China). MAP, HR, rate pressure product (RPP; the product of HR and systolic blood pressure), CVP, SpO2, CO, SV, and BIS were recorded 10 min before and 10, 30, 60 min after the initiation of anesthesia and the conclusion of surgery. The duration of surgery, recovery time from anesthesia, the incidence of intra-operative hypertension and hypotension $(\geq \pm 30 \%$ of baseline), and the dosages of fentanyl and propofol were calculated.

\section{Cognitive function assessment}

MMSE was administered to all patients by a single psychologist to assess cognitive functions on one day preoperatively, and post-operative days one, three, and seven. Assessed cognitive functions included 1) time orientation ( five points, maximum ) and spatial orientation ( five points ); 2) short-term memory ( three points ) and delayed memory ( three points ); 3) language function: naming ( two points ), repeating ( one point) and writing ( one point ); 4) executive function ( five points ), and 5) calculation ( five points ). The total maximum score was 30. POCD was defined as a post-operative decrease in MMSE score by $\geq 2$ points, as compared with the patient's pre-operative score $e^{8,31,32}$. All patients stayed in the hospital for at least 7 days after the surgical procedure. 


\section{Statistical analysis}

Analyses were performed using the SPSS statistical software package, version 15.0 (SPSS Inc., Chicago, IL, USA). Sample size estimation was determined by one-way analysis of variance (ANOVA) power analysis. A sample size of 340 subjects ( $n=68$ for each group) was sufficient todetect differences in the means among the five groups, with a statistical power of $>90 \%$. All numerical values are presented as mean with standard deviation. Repeated measures ANOVA was used to compare intra-group differences, and one-way ANOVA was used to compare inter-group differences. Categorical data were compared using the chi-square test. Univariate regression analysis and multivariate logistic regression model were used to examine the relations between peri-operative risk factors and POCD. The odds ratio (OR) value and corresponding $95 \%$ confidence interval(CI) were calculated as well. P-values $<0.05$ was considered indicative of statistical significance.

\section{Results}

Table 1 summarizes the clinical characteristics of patients in groups A, B, C, D, and E. There were no significant differences in gender, age, body weight, and ASA scores among the five groups $(\mathrm{P}>0.05)$. The percentage of complications such as hypertension, coronary diseases, and pulmonary diseases did not differ significantly among groups ( $p>0.05)$.

Table 1. Clinical characteristics of patients $(n=68$ for each group)

\begin{tabular}{|c|c|c|c|c|c|c|c|}
\hline $\begin{array}{c}\text { Sex } \\
\text { (male/female) }\end{array}$ & $\begin{array}{c}\text { Age } \\
\text { (years) }\end{array}$ & $\begin{array}{c}\text { Body } \\
\text { weight } \\
\text { (kg) }\end{array}$ & $\begin{array}{c}\text { ASA } \\
\text { (II/III) }\end{array}$ & $\begin{array}{c}\text { Hypertension } \\
(\%)\end{array}$ & $\begin{array}{l}\text { Coronary } \\
\text { diseases } \\
(\%)\end{array}$ & $\begin{array}{l}\text { Pulmonary } \\
(\%)\end{array}$ & diseases \\
\hline $32 / 36$ & $81.5 \pm 4.5$ & $73.4 \pm 13.4$ & $53 / 15$ & 26.5 & 29.4 & 22.1 & \\
\hline $33 / 35$ & $80.5 \pm 5.5$ & $73.7 \pm 12.8$ & $55 / 13$ & 29.4 & 30.8 & 25.0 & \\
\hline $31 / 37$ & $82.5 \pm 4.5$ & $74.1 \pm 11.5$ & $52 / 16$ & 27.9 & 26.5 & 26.5 & \\
\hline $33 / 35$ & $81.5 \pm 5.5$ & $73.7 \pm 12.3$ & $54 / 14$ & 29.4 & 32.4 & 27.9 & \\
\hline $34 / 34$ & $82.5 \pm 6.5$ & $75.1 \pm 11.8$ & $55 / 13$ & 30.8 & 27.9 & 25.0 & \\
\hline
\end{tabular}

Table 2 summarizes the hemodynamic parameters of patients in the five groups at $10 \mathrm{~min}$ before anesthesia, 10 $\mathrm{min}, 30 \mathrm{~min}$, and $60 \mathrm{~min}$ after anesthesia, and at the conclusion of surgery. At $30 \mathrm{~min}$ and $60 \mathrm{~min}$ after anesthesia, and at the conclusion of surgery, the HR was significantly faster in Groups A and C compared with Group E (p $<0.05)$. The RPR value was significantly lower in Groups $\mathrm{B}$ and D compared with Group E $(\mathrm{p}<0.05)$. The $\mathrm{SpO}_{2}$ values were within the normal range for all groups during the operation. 
Table 2. The hemodynamic parameters of patients in Groups A, B, C, D and E

\begin{tabular}{|c|c|c|c|c|c|}
\hline Parameter & $\begin{array}{c}\text { Group A } \\
(n=68)\end{array}$ & $\begin{array}{c}\text { Group B } \\
(n=68)\end{array}$ & $\begin{array}{c}\text { Group C } \\
(n=68)\end{array}$ & $\begin{array}{l}\text { Group D } \\
(n=68)\end{array}$ & $\begin{array}{r}\text { Group E } \\
(n=68)\end{array}$ \\
\hline $\begin{array}{l}\text { MAP }(\mathrm{mmHg}) \\
10 \quad \min \text { before } \\
\text { anesthesia }\end{array}$ & $89.1 \pm 8.6$ & $88.3 \pm 8.8$ & $88.5 \pm 8.9$ & $89.3 \pm 8.5$ & $89.7 \pm 8.7$ \\
\hline $\begin{array}{l}10 \text { min after anesthesia } \\
30 \text { min after anesthesia } \\
60 \text { min after anesthesia } \\
\text { Conclusion of surgery }\end{array}$ & $\begin{array}{l}76.1 \pm 5.3^{\mathrm{a}} \\
88.4 \pm 9.4^{\mathrm{b}} \\
88.6 \pm 12.3^{\mathrm{b}} \\
86.5 \pm 117^{\mathrm{b}}\end{array}$ & $\begin{array}{c}77.3 \pm 5.2^{\mathrm{a}} \\
88.4 \pm 9.8^{\mathrm{b}} \\
89.1 \pm 13.2^{\mathrm{b}} \\
88.7 \pm 125^{\mathrm{b}}\end{array}$ & $\begin{array}{c}75.7 \pm 4.8^{\mathrm{a}} \\
85.9 \pm 9.6^{\mathrm{b}} \\
87.2 \pm 12.7^{\mathrm{b}} \\
88.1 \pm 13.2^{\mathrm{b}}\end{array}$ & $\begin{array}{l}74.7 \pm 5.5^{\mathrm{a}} \\
84.9 \pm 9.5^{\mathrm{b}} \\
87.6 \pm 11.9^{\mathrm{b}} \\
89.3 \pm 12.7^{\mathrm{b}}\end{array}$ & $\begin{array}{l}75.8 \pm 5.3^{\mathrm{a}} \\
99.5 \pm 9.7^{\mathrm{a}} \\
100.7 \pm 11.1^{\mathrm{a}} \\
105.6 \pm 11.2^{\mathrm{a}}\end{array}$ \\
\hline $\begin{array}{l}\text { HR (beats/min) } \\
10 \quad \text { min before } \\
\text { anesthesia } \\
10 \text { min after anesthesia } \\
30 \text { min after anesthesia } \\
60 \text { min after anesthesia } \\
\text { Conclusion of surgery }\end{array}$ & $\begin{array}{c}85.1 \pm 11.4 \\
70.7 \pm 8.2^{\mathrm{a}} \\
104.1 \pm 10.3^{\mathrm{a} \mathrm{b}} \\
104.9 \pm 11.1^{\mathrm{a}} \\
103.9 \pm 11.8^{\mathrm{a} b}\end{array}$ & $\begin{array}{l}83.7 \pm 12.6 \\
69.5 \pm 9.3^{\mathrm{a}} \\
81.7 \pm 11.1 \\
83.5 \pm 10.4 \\
82.8 \pm 10.5 \\
\end{array}$ & $\begin{array}{c}83.7 \pm 11.6 \\
71.5 \pm 8.6^{\mathrm{a}} \\
103.7 \pm 11.3^{\mathrm{a} b} \\
105.5 \pm 10.5^{\mathrm{a}} \mathrm{b} \\
107.7 \pm 11.7^{\mathrm{ab}}\end{array}$ & $\begin{array}{l}83.4 \pm 11.5 \\
70.2 \pm 9.3^{\mathrm{a}} \\
82.6 \pm 10.9 \\
815 \pm 11.8 \\
82.7 \pm 12.1 \\
\end{array}$ & $\begin{array}{l}85.4 \pm 12.5 \\
71.5 \pm 9.6^{\mathrm{a}} \\
89.3 \pm 12.0 \\
88.5 \pm 11.5 \\
85.5 \pm 11.6\end{array}$ \\
\hline $\begin{array}{l}\text { PRP } \\
10 \text { min before } \\
\text { anesthesia } \\
10 \text { min after anesthesia } \\
30 \text { min after anesthesia } \\
60 \text { min after anesthesia } \\
\text { Conclusion of surgery }\end{array}$ & $\begin{array}{l}10846.7 \pm 331.6 \\
8471.2 \pm 179.9^{\mathrm{a}} \\
11279.5 \pm 319.5 \\
12399.4 \pm 341.1 \\
12492.8 \pm 350.4\end{array}$ & $\begin{array}{c}10823.7 \pm 319.7 \\
8501.2 \pm 197.5^{\mathrm{a}} \\
10621.1 \pm 321.7^{\mathrm{b}} \\
10544.2 \pm 321.8^{\mathrm{b}} \\
10701.3 \pm 325.5^{\mathrm{b}}\end{array}$ & $\begin{array}{c}10811.5 \pm 319.7 \\
8471.3 \pm 196.1^{\mathrm{a}} \\
12779.3 \pm 321.2^{\mathrm{a}} \\
12861.4 \pm 335.6^{\mathrm{a}} \\
12866.6 \pm 339.7^{\mathrm{a}}\end{array}$ & $\begin{array}{l}10749.8 \pm 332.5 \\
8502.3 \pm 195.5^{\mathrm{a}} \\
10807.4 \pm 351.1^{\mathrm{b}} \\
10784.3 \pm 360.3^{\mathrm{b}} \\
10771.7 \pm 345.7^{\mathrm{b}}\end{array}$ & $\begin{array}{c}10761.3 \pm 341.7 \\
8523.6 \pm 198.2^{\mathrm{a}} \\
13217.1 \pm 377.6^{\mathrm{a}} \\
13203.5 \pm 357.3^{\mathrm{a}} \\
13119.2 \pm 379.5^{\mathrm{a}}\end{array}$ \\
\hline $\begin{array}{l}\mathrm{CVP}\left(\mathrm{cmH}_{2} \mathrm{O}\right) \\
10 \text { min before } \\
\text { anesthesia } \\
10 \text { min after anesthesia } \\
30 \text { min after anesthesia } \\
60 \text { min after anesthesia } \\
\text { Conclusion of surgery }\end{array}$ & $\begin{array}{l}8.7 \pm 1.0 \\
6.6 \pm 1.1^{\mathrm{a}} \\
8.9 \pm 1.1 \\
8.8 \pm 1.2 \\
8.6 \pm 1.2\end{array}$ & $\begin{array}{l}8.5 \pm 1.2 \\
6.3 \pm 1.1^{\mathrm{a}} \\
8.7 \pm 1.3 \\
8.7 \pm 1.2 \\
8.5 \pm 1.0\end{array}$ & $\begin{array}{l}8.6 \pm 1.1 \\
6.5 \pm 1.1^{\mathrm{a}} \\
8.7 \pm 1.2 \\
8.8 \pm 1.1 \\
8.9 \pm 1.1 \\
\end{array}$ & $\begin{array}{l}8.4 \pm 1.3 \\
6.4 \pm 1.1^{\mathrm{a}} \\
8.6 \pm 1.1 \\
8.7 \pm 1.1 \\
8.5 \pm 1.2\end{array}$ & $\begin{array}{l}8.5 \pm 1.2 \\
6.3 \pm 1.2^{\mathrm{a}} \\
8.9 \pm 1.0 \\
8.8 \pm 1.1 \\
8.7 \pm 1.0\end{array}$ \\
\hline $\begin{array}{l}\mathrm{SpO}_{2}(\%) \\
10 \quad \text { min before } \\
\text { anesthesia } \\
10 \text { min after anesthesia } \\
30 \text { min after anesthesia } \\
60 \text { min after anesthesia } \\
\text { Conclusion of surgery }\end{array}$ & $\begin{array}{l}98.0 \pm 1.3 \\
98.3 \pm 1.2 \\
98.4 \pm 1.1 \\
98.5 \pm 1.0\end{array}$ & $\begin{array}{l}98.2 \pm 1.3 \\
98.3 \pm 1.0 \\
98.3 \pm 1.1 \\
98.2 \pm 1.0\end{array}$ & $\begin{array}{l}98.2 \pm 1.5 \\
97.8 \pm 1.3 \\
98.2 \pm 1.1 \\
98.2 \pm 1.4\end{array}$ & $\begin{array}{l}98.4 \pm 1.1 \\
98.5 \pm 1.0 \\
98.4 \pm 0.9 \\
98.3 \pm 1.1\end{array}$ & $\begin{array}{l}98.1 \pm 1.2 \\
98.2 \pm 1.1 \\
98.3 \pm 1.2 \\
98.3 \pm 1.0\end{array}$ \\
\hline $\begin{array}{l}\mathrm{CO}(\mathrm{L} / \mathrm{min}) \\
10 \quad \text { min } \\
\text { anesthesia } \\
10 \text { min after anesthesia } \\
30 \text { min after anesthesia } \\
60 \text { min after anesthesia } \\
\text { Conclusion of surgery }\end{array}$ & $\begin{array}{l}7.31 \pm 1.09 \\
5.19 \pm 1.11 \\
7.24 \pm 1.07^{\mathrm{b}} \\
7.29 \pm 1.11^{\mathrm{b}} \\
7.35 \pm 1.20^{\mathrm{b}}\end{array}$ & $\begin{array}{l}7.35 \pm 1.11 \\
5.23 \pm 1.10^{\mathrm{a}} \\
7.26 \pm 1.10^{\mathrm{b}} \\
7.25 \pm 1.10^{\mathrm{b}} \\
7.32 \pm 1.13^{\mathrm{b}}\end{array}$ & $\begin{array}{l}5.22 \pm 1.12^{\mathrm{a}} \\
7.32 \pm 1.10^{\mathrm{b}} \\
7.36 \pm 1.11^{\mathrm{b}} \\
7.39 \pm 1.13^{\mathrm{b}}\end{array}$ & $\begin{array}{l}7.29 \pm 1.14 \\
5.25 \pm 1.11^{\mathrm{a}} \\
7.34 \pm 1.12^{\mathrm{b}} \\
7.38 \pm 1.17^{\mathrm{b}} \\
7.40 \pm 1.12^{\mathrm{b}}\end{array}$ & $\begin{array}{l}7.34 \pm 1.13 \\
5.29 \pm 1.14^{\mathrm{a}} \\
9.17 \pm 1.31^{\mathrm{a}} \\
9.26 \pm 1.30^{\mathrm{a}} \\
9.27 \pm 1.34^{\mathrm{a}}\end{array}$ \\
\hline $\begin{array}{l}\text { SV }(\mathrm{ml} / \text { beat }) \\
10 \text { min before } \\
\text { anesthesia } \\
10 \text { min after anesthesia } \\
30 \text { min after anesthesia } \\
60 \text { min after anesthesia } \\
\text { Conclusion of surgery }\end{array}$ & $\begin{array}{l}85.1 \pm 11.4 \\
67.5 . \pm 10.1^{\mathrm{a}} \\
84.7 \pm 12.5^{\mathrm{b}} \\
86.1 \pm 12.3^{\mathrm{b}} \\
87.4 \pm 12.7^{\mathrm{b}}\end{array}$ & $\begin{array}{l}84.4 \pm 11.1 \\
67.1 \pm 11.3^{\mathrm{a}} \\
83.7 \pm 11.5^{\mathrm{b}} \\
85.1 \pm 10.9^{\mathrm{b}} \\
88.7 \pm 12.6^{\mathrm{b}}\end{array}$ & $\begin{array}{l}84.5 \pm 10.7 \\
70.1 \pm 10.2^{\mathrm{a}} \\
84.8 \pm 12.3^{\mathrm{b}} \\
86.9 \pm 12.0^{\mathrm{b}} \\
87.7 \pm 13.1^{\mathrm{b}}\end{array}$ & $\begin{array}{l}85.1 \pm 11.3 \\
68.4 \pm 10.7^{\mathrm{a}} \\
84.9 \pm 11.2^{\mathrm{b}} \\
84.5 \pm 12.0^{\mathrm{b}} \\
86.9 \pm 12.2^{\mathrm{b}}\end{array}$ & $\begin{array}{l}85.2 \pm 11.6 \\
68.9 . \pm 11.0^{\mathrm{a}} \\
95.5 \pm 11.3^{\mathrm{a}} \\
97.5 \pm 12.2^{\mathrm{a}} \\
98.8 \pm 12.9^{\mathrm{a}}\end{array}$ \\
\hline
\end{tabular}

Table 3 summarizes the operation duration, recovery time from anesthesia, and dosage of fentanyl, propofol, nicardipine and nitroglycerin among the five groups. There was no significant difference in the operation duration among groups $(\mathrm{p}>0.05)$. There was no significant difference in the dosage of nicardipine between Groups
$\mathrm{A}$ and $\mathrm{B}$ and in the dosage of nitroglycerin between Groups $C$ and D ( $p>0.05)$. The recovery time from anesthesia was significantly shorter in Groups A, B, C, and D compared with Group E ( $p<0.05)$. The dosages of fentanyl and propofol were significantly lower in Groups A, B, C, and D compared with Group E ( $<<0.05)$. 
Table 3. The operation time; recovery time; and dosage of anesthetics, nicardipine, and nitroglycerin in Groups $A, B, C, D$, and $E(n=68)$

\begin{tabular}{|c|c|c|c|c|c|c|}
\hline Group & $\begin{array}{c}\text { Operation time } \\
(\text { min) }\end{array}$ & $\begin{array}{l}\text { Recovery time } \\
\text { (min) }\end{array}$ & $\begin{array}{c}\text { Fentanyl } \\
\text { (mg) }\end{array}$ & $\begin{array}{c}\text { Propofol } \\
\text { (mg) }\end{array}$ & $\begin{array}{l}\text { Nicardipine } \\
(\mu \mathrm{g} / \mathrm{kg} / \mathrm{min})\end{array}$ & $\begin{array}{r}\text { Nitroglycerin } \\
(\mu \mathrm{g} / \mathrm{kg} / \mathrm{min})\end{array}$ \\
\hline A & $196.7 \pm 19.8$ & $8.9 \pm 2.5^{\mathrm{a}}$ & $0.33 \pm 0.02^{\mathrm{a}}$ & $605.2 \pm 21.5^{\mathrm{a}}$ & $5.3 \pm 2.4$ & \\
\hline B & $201.5 \pm 22.5$ & $8.7 \pm 2.3^{\mathrm{a}}$ & $0.32 \pm 0.02^{\mathrm{a}}$ & $603.7 \pm 25.2^{\mathrm{a}}$ & $5.1 \pm 2.3$ & -.- \\
\hline $\mathrm{C}$ & $198.5 \pm 23.7$ & $8.9 \pm 2.1^{\mathrm{a}}$ & $0.35 \pm 0.03^{\mathrm{a}}$ & $601.5 \pm 19.8^{\mathrm{a}}$ & -1.-- & $5.5 \pm 2.6$ \\
\hline D & $203.5 \pm 20.6$ & $9.1 \pm 2.2^{\mathrm{a}}$ & $0.33 \pm 0.03^{\mathrm{a}}$ & $604.4 \pm 22.6^{\mathrm{a}}$ & - & $5.3 \pm 2.5$ \\
\hline E & $199.5 \pm 22.4$ & $17.4 \pm 7.1$ & $0.46 \pm 0.05$ & $877.5 \pm 32.4$ & -1.-- & $\ldots$ \\
\hline
\end{tabular}

Table 4 summarizes the MMSE scores of patients in the five groups one day pre-operatively, and on post-operative days one, three, and seven. There was no significant difference in the all pre-operative MMSE scores among groups. The MMSE scores in Groups C, D, and $\mathrm{E}$, but not Groups A and B, were significantly lower on post-operative days one and three compared with those one day pre-operatively ( $p<0.05)$. On post-operative days one and three, the MMSE scores in Groups A and
B were significantly higher than those in Groups C, D, and $E(p<0.05)$.There was no significant difference in the MMSE scores among groups on post-operative day seven $(p>0.05)$. The frequencies of occurrence of POCD in Groups A, B, C, D, and E were 4.4\%, 4.4\%, $13.2 \%, 11.8 \%$, and $25.0 \%$, respectively, and the incidence of POCD in Groups A, B occurred significantly less frequently compared with Group C, D and E $(\mathrm{p}<0.01$ or 0.05). Complications, such as intracranial hemorrhage, were absent in all five groups.

Table 4. MMSE scores, and POCD incidence in Groups A, B, C, D, and E $(\mathbf{n}=68)$

\begin{tabular}{lcccccc}
\hline Group & $\mathbf{T}_{\mathbf{1}}$ & $\mathbf{T}_{\mathbf{2}}$ & $\mathbf{T}_{\mathbf{3}}$ & $\mathbf{T}_{\mathbf{4}}$ & POCD (n) & POCD incidence (\%) \\
\hline A & $27.9 \pm 2.0$ & $27.6 \pm 2.1^{\mathrm{bcd}}$ & $27.8 \pm 2.2^{\mathrm{bcd}}$ & $27.8 \pm 2.3$ & $3^{\text {cde }}$ & $4.4^{\text {cde }}$ \\
B & $27.8 \pm 1.9$ & $27.7 \pm 2.1^{\mathrm{bcd}}$ & $27.5 \pm 2.0^{\mathrm{bcd}}$ & $27.9 \pm 2.0$ & $3^{\text {cde }}$ & $4.4^{\text {cde }}$ \\
C & $27.9 \pm 2.1$ & $25.3 \pm 2.0^{\mathrm{a}}$ & $25.2 \pm 2.1^{\mathrm{a}}$ & $27.9 \pm 1.9$ & $9^{\mathrm{b}}$ & $13.2^{\mathrm{b}}$ \\
D & $27.8 \pm 2.0$ & $25.5 \pm 2.2^{\mathrm{a}}$ & $25.4 \pm 2.0^{\mathrm{a}}$ & $27.7 \pm 2.2$ & $8^{\mathrm{b}}$ & $11.8^{\mathrm{b}}$ \\
E & $27.9 \pm 2.0$ & $24.4 \pm 2.3^{\mathrm{a}}$ & $24.4 \pm 2.2^{\mathrm{a}}$ & $27.8 \pm 2.1$ & 17 & 25 \\
\hline
\end{tabular}

T1: one day preoperatively; T2: postoperative day one, T3: postoperative day three; T4: postoperative day seven ${ }^{\mathrm{a}} p<0.05$ vs. T1; ${ }^{\mathrm{b}} p<0.05$ vs. Group E; ${ }^{\mathrm{c}} p<0.05$ vs. Group C; ${ }^{\mathrm{d}} p<0.05 \mathrm{vs}$. Group D; ${ }^{\mathrm{e}} p<0.01$ vs. Group E

Table 5 shows that the drug regimens in Groups A, B, and $\mathrm{E}$ and the doses of propofol and fentanyl were risk factors for POCD. The duration of hypertension and hypotension was less than 3 minutes. 
Table 5. Univariate regression analysis of risk factors for POCD

\begin{tabular}{lcccc}
\hline \multicolumn{1}{c}{ Parameters } & POCD $(\mathrm{n}=41)$ & POCD & $\begin{array}{c}\text { Non- } \\
(\mathrm{n}=299)\end{array}$ & $p$-value \\
\hline Sex (male/female) & $19 / 22$ & $137 / 162$ & ------ \\
Average Age (years) & $82.5 \pm 3.5$ & $81.5 \pm 4.5$ & 0.085 \\
Body weight (kg) & $75.2 \pm 11.5$ & $75.7 \pm 11.4$ & 0.672 \\
ASA (II/III) & $32 / 9$ & $237 / 62$ & ------ \\
Preoperative hypertension (\%) & $13(31.7)$ & $85(28.4)$ & 0.079 \\
Coronary diseases (\%) & $12(29.3)$ & $88(29.4)$ & 0.086 \\
Pulmonary diseases (\%) & $11(26.8)$ & $75(25.1)$ & 0.078 \\
MMSE <26 (\%) & $7(17.1)$ & $34(11.4)$ & 0.107 \\
Asymptomatic large artery & $8(19.5)$ & $54(18.1)$ & 0.089 \\
atherosclerosis(\%) & $15(36.6)$ & $95(31.8)$ & 0.091 \\
$\geq 80 y$ (\%) & & &
\end{tabular}

Table 6 showed that there were significant associations between POCD and drug intervention methods in groups A, B.

Table 6. Multivariate logistic regression of risk factors for POCD

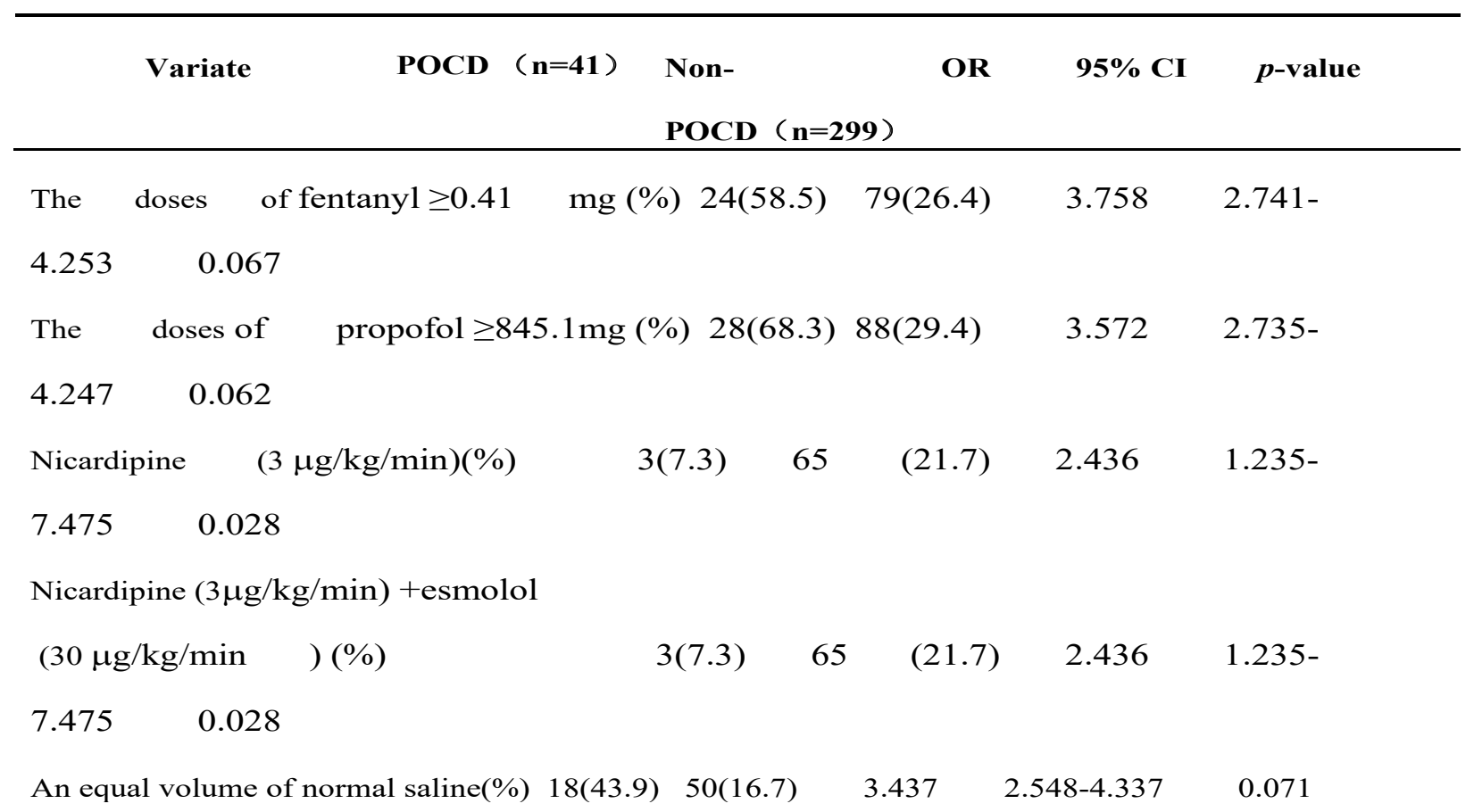




\section{Discussion}

POCD is a decline in cognitive function induced by surgery and anesthesia. The pathogenesis of POCD is multifactorial and is associated with disturbances in the central nervous system, endocrine, and immune systems ${ }^{33}$. It is well known that the risk of POCD increases with age, and that the elderly are at a high risk for a long-term cognitive problems ${ }^{34}$. With the growth in the elderly population, there will likely be an increase in the number of elderly patients who undergo surgery, and thus, the incidence of POCD will be expected to increase. POCD leads to increased cost, prolonged length of hospital stay, and decreased quality of life for patients, thus increasingly becoming a serious medical, economic, and social issue $^{35,36}$. Because the elderly (aged 70 years or older) exhibit increased sensitivity to drugs, and also often exhibit medical profiles complicated by many diseases_-such as hypertension, coronary heart disease, and diabetes, and pulmonary diseases - they generally show reduced tolerance for surgery and anesthesia and an incidence of POCD reported to be as high as $25.8 \%$ within one week after non-cardiac surgery ${ }^{3}$. Therefore, identifying the etiology of POCD and exploring a method to reduce its incidence are important for improving postoperative quality of life in elderly patients. Since POCD frequently occurs in elderly patients undergoing cardiac surgery ${ }^{37}$, the present study selected elderly patients for study who were undergoing radiofrequency ablation of atrial fibrillation in order to investigate the impact on POCD of hemodynamic stability induced by nicardipine, nitroglycerin, or their combination with esmolol. All patients received anticoagulants to minimize the risk of microemboli formation.

MMSE is a widely used simple method for clinically evaluating cognitive function with high reliability ${ }^{8,31,32}$. In the present study, we used MMSE to evaluate the cognitive status in elderly patients after radiofrequency ablation of atrial fibrillation. POCD is a severe central nervous system complication after surgery. Since the etiology of POCD remains unclear, it is difficult to prevent and treat the condition. It is therefore critical to identify risk factors beyond age and surgery for the purpose of reducing their influence on the occurrence of POCD in the elderly. Since elderly patients often have various degrees of heart diseases, maintenance of a balance of stable hemodynamics and myocardial oxygen supply and demand is important for preventing the occurrence of $\mathrm{POCD}^{37}$, ${ }^{38,39}$. In the present study, we investigated the effects of hemodynamic stability induced by nicardipine and nitroglycerin and their pairwise combination with esmolol on POCD in elderly patients after radio-frequency ablation of atrial fibrillation. At $30 \mathrm{~min}$ and $60 \mathrm{~min}$ after anesthesia and at the conclusion of surgery, the HR was significantly faster in groups A and C compared with control group E. The RPP value was significantly lower in groups $\mathrm{B}$ and $\mathrm{D}$ compared with group $\mathrm{E}$. The MAP, CO, and SV values were significantly lower in groups $A, B, C$, and D compared with group $\mathrm{E}$. These findings suggested that nicardipine, nitroglycerin, and their combination with esmolol facilitated maintenance of stable hemodynamics in these patients. In addition, in this study, the incidences of POCD in Groups A, B, C, D, and E were 4.4\%, 4.4\%, $13.2 \%, 11.8 \%$, and $25.0 \%$, respectively, and the incidence of POCD in Groups A, B occurred significantly less frequently compared with Groups C, D, and E $(p<0.01$ or 0.05). The dosages of fentanyl and propofol were significantly lower in Groups A, B, C, and D compared to those in Group $\mathrm{E}(\mathrm{p}<0.05)$. Univariate regression analysis identified the doses of propofol and fentanyl as risk factors for POCD, thereby suggesting that the high incidence of POCD in elderly patients in the control group may be related to the high doses of fentanyl and propofol used in that group. Therefore, it may be inferred that in addition to drug intervention, proper anesthesia management may help minimize the incidence of POCD.

POCD is reported to be associated with transient ischemic attack induced by microemboli caused by radiofrequency ablation for atrial fibrillation ${ }^{40}$. In the current study, we found that multivariate logistic regression analysis showed significant associations between the incidence of POCD and drug regimens in Groups A and B, which had the lowest incidences of POCD, thereby suggesting that nicardipine alone or in combination with esmolol issuperior to nitroglycerin alone or in combination with esmolol in minimizing the incidence of POCD. Nicardipine is highly lipophilic, and therefore readily transits the blood brain barrier, thus rapidly achieving a high brain concentration. Nicardipine can ameliorate the cerebral uptake of glucose and lactate, reduce cerebral oxygen consumption, increase cerebral OCI, and protect neurons ${ }^{16,19}$; this results in an improvement in the physiological functions of the hippocampus, anterior cerebral white matter, basal 
ganglia, and pre-frontal cortex and consequently reducing the incidence of POCD. In contrast, nitroglycerin has been reported to produce no effect on cerebral blood flow ${ }^{41-43}$, and therefore, it cannot ameliorate the cerebral uptake of glucose and lactate and increase cerebral OCI. Thus, the incidence of POCD with nitroglycerine is higher than that with nicardipine. In this study, the incidences of POCD were the same in Groups A and B, while those in Groups C and D showed no significant difference, thereby suggesting that esmolol may produce no effect on cerebral metabolism ${ }^{20,21}$. In addition, although the use of nicardipine entails the risk of intracranial hemorrhage by dilating cerebrovascular blood vessels to increase baseline $\mathrm{rCBF}$, none of the patients in this study developed intracranial hemorrhage. This may be attributed to the relative low dose of nicardipine used in our study in order to maintain a relatively stable blood pressure level.

\section{Conclusion}

We investigated the effects of nicardipine, nitroglycerin, and their pairwise combination with esmolol for achieving maintenance of hemodynamic stability on POCD in elderly patients undergoing radiofrequency ablation of atrial fibrillation. We found that maintenance of stable intraoperative hemodynamics by nicardipine and nitroglycerin or their combination with esmolol all could reduce the occurrence of POCD, and use of nicardipine or combined with esmolol can be superior to other protocols in reducing POCD in elderly patients. The use of nicardipine combined with esmolol can be superior to nicardipine alone in reducing POCD in elderly patients with potential cardiovascular diseases.

\section{Acknowledgements}

We want to thank those who assisted in the preparation of this manuscript. This study was supported by the Science and Technology Panning Project of Dalian Municipal Government in 2012.

\section{Supporting information captions}

S1 Text-Study Plan for Comparison of Esmolol Combined with Nicardipine or Nitroglycerin in Post-operative Cognitive Dysfunction

S2 Text-Ethics statement

S3 Text: Flow Diagram

S4 Text: Study Plan for Comparison of Esmolol Combined with Nicardipine or Nitroglycerin in Post-operative Cognitive Dysfunction (In Chinese)

\section{Conflict of interest}

None to declare.

\section{References}

1. Fong HK, Sands LP, Leung JM.The role of postoperative analgesia in delirium and cognitive decline in elderly patients: a systematic review. Anesth Analg. 2006; 102:1255-1266.

2. Johnson T, Monk T, Rasmussen LS, Abildstrom H, Houx P, Korttila K, et al.Postoperative cognitive dysfunction in middle-aged patients. Anesthesiology. 2002; 96: 1351-1357 PubMed.

3. Moller JT, Cluitmans P, Rasmussen LS, Houx P, Rasmussen $\mathrm{H}$, Canet J, et al.Long-term postoperative cognitive dysfunction in the elderly ISPOCD1 study. ISPOCD investigators. International Study of Post-Operative Cognitive Dysfunction. Lancet. 1998; 351: 857-861.

4. Williams-Russo P, Sharrock NE, Mattis S, Szatrowski TP, Charlson ME.Cognitive effects after epidural vs general anesthesia in older adults. A randomized trial. JAMA. 1995; 274: 44-50 PubMed.

5. Morandi A, Pandharipande PP, Jackson JC, Bellelli G, Trabucchi M, Ely EW.Understanding terminology of delirium and long-term cognitive impairment in critically ill patients. Best Pract Res Clin Anaesthesiol. 2012; 26: 267-276. 6. Rasmussen LS.Postoperative cognitive dysfunction: incidence and prevention. Best Pract Res Clin Anaesthesiol. 2006; 20: 315-330.

7. Monk TG, Weldon BC, Garvan CW, Dede DE, van der Aa MT, Heilman KM, et al.Predictors of cognitive dysfunction after major noncardiac surgery. Anesthesiology. 2008; 108: 18-30.

8. Fines DP, Severn AM.Anaesthesia and cognitive disturbance in the elderly. Critical Care \& Pain. 2006; 6:37-40 9. Fabricius-Bjerre A, Overgaard A, Winther-Olesen M, Lönn L, Secher NH, Nielsen HB. Reduced cerebral oxygen-carbohydrate index during endotracheal intubation in vascular surgical patients. Clin Physiol Funct Imaging. 2015; 35(5): 404-410.

10. Ide K, Horn A, Secher NH. Cerebral metabolic response to submaximal exercise. J Appl Physiol. 1999; 87: 1604-1608. PubMed

11. Ide K, Schmalbruch IK, Quistorff B, Horn A,Secher NH. Lactate, glucose and O2 uptake in human brain during recovery from maximal exercise. J Physiol. 2000; 522: 159-164. PubMed

12. Dalsgaard MK. Fuelling cerebral activity in exercising man. J Cereb Blood Flow Metab. 2006; 26: 731-750. 
13. Rasmussen P, Nyberg N, Jaroszewski JW, Krogh-Madsen R, Secher NH, Quistorff B.Brain non-oxidative carbohydrate consumption is not explained by export of an unknown carbon source: evaluation of the arterial and jugular venous metabolome. J Cereb Blood Flow Metab. 2010; 30: 1240-1246.

14. Groeben H, Schafer B, Pavlakovic G, Silvanus MT, Peters J. Lung function under high thoracic segmental epidural anesthesia with ropivacaine or bupivacaine in patients with severe obstructive pulmonary disease undergoing breast surgery Anesthesiology. 2002; 96(3): 536541.

15. Fleisher LA, Anderson GF. Perioperative risk: how can we study the influence of provider characteristics ? Anesthesiology. 2002; 96(5): 1039-1041. PubMed

16. Larsen TS, Rasmussen P, Overgaard M, Secher NH, Nielsen HB. Non-selective b-adrenergic blockade prevents reduction of the cerebral metabolic ratio during exhaustive exercise in humans. J Physiol. 2008; 586: 28072815.

17. Newman S, Stygall J, Hirani S, Shaefi S, Maze M. Postoperative cognitive dysfunction after noncardiac surgery: a systematic review. Anesthesiology. 2007; 106: 572- 590. PubMed

18. Fang Q, Qian X, An J, Wen H, Cope DK, Williams JP.Higher dose dexamethasone increases early postoperative cognitive dysfunction. J Neurosurg Anesthesiol. 2014; 26: 220-225.

19. Li Q , Jiang W. Progress of postoperative cognitive dysfunction. Medical Recapitulate (China). 2010; 16(2):231234.

20. Seifert T, Secher NH. Sympathetic influence on cerebral blood flow and metabolism during exercise in humans. Prog Neurobiol. 2011; 95(3):406-426. PubMed

21. Gam CMB, Rasmussen P, Secher NH, Seifert T, Larsen FS, Nielsen HB. Maintained cerebral metabolic ratio during exercise in patients with b-adrenergic blockade. Clin Physiol Funct Imaging. 2009; 29: 420-426.

22. Quistorff B, Secher NH, Van Lieshout JJ. Lactate fuels the human brain during exercise. FASEB J. 2008; 22: 3443-3449. PubMed

23. Nybo L, Nielsen B, Blomstrand E, Moller K, Secher N. Neurohumoral responses during prolonged exercise in humans. J Appl Physiol. 2003; 95: 1125-1131. PubMed 24. Peacock WFt, Hilleman DE, Levy PD, Rhoney DH, Varon J.A systematic review of nicardipine vs labetalol for the management of hypertensive crises. Am J Emerg Med. 2012; 30: 981-993.

25. Carlson MD, Eckman PM.Review of vasodilators in acute decompensated heart failure: the old and the new. $J$ Card Fail. 2013; 19:478-493.

26. Degoute CS.Controlled hypotension: a guide to drug choice. Drugs. 2007; 67: 1053-1076 PubMed .

27. Hersey SL, O'Dell NE, Lowe S, Rasmussen G, Tobias JD, Deshpande JK, et al.Nicardipine versus nitroprusside for controlled hypotension during spinal surgery in adolescents. Anesth Analg. 1997; 84: 1239-1244.

28. Kovac AL, Masiongale A.Comparison of nicardipine versus esmolol in attenuating the hemodynamic responses to anesthesia emergence and extubation. J Cardiothorac Vasc Anesth. 2007; 21: 45-50.

29. Llau JV, de Andres J, Gomar C, Gomez A, Hidalgo F, Sahagun J, et al.Drugs that alter hemostasis and regional anesthetic techniques: safety guidelines. Consensus conference. Rev Esp Anestesiol Reanim. 2001; 48: 270-278.

30. Lustik SJ, Papadakos PJ, Jackman KV, Rubery PT, Jr., Kaplan KL, Chhibber AK.Nicardipine versus nitroprusside for deliberate hypotension during idiopathic scoliosis repair. J Clin Anesth. 2004; 16: 25-33 PubMed.

31. Anthony JC, LeResche L, Niaz U, von Korff MR, Folstein MF.Limits of the 'Mini-Mental State' as a screening test for dementiaand delirium among hospital patients. Psychol Med. 1982; 12: 397-408.

32. Perrier V, Julliac B, Lelias A, Morel N, Dabadie P, Sztark F.Influence of the fascia iliaca compartment block on postoperative cognitive status in the elderly. Ann Fr Anesth Reanim. 2010; 29: 283-288.

33. Krenk L, Rasmussen LS, Kehlet H.New insights into the pathophysiology of postoperative cognitive dysfunction. Acta Anaesthesiol Scand. 2010; 54: 951-956.

34. Fidalgo AR.Experimental insights into age-exacerbated cognitive dysfunction after peripheral surgery. Aging Cell. 2013; 12: 523-524.

35. Brooks P, Spillane JJ, Dick K, Stuart-Shor E.Developing a strategy to identify and treat older patients with postoperative delirium. AORN J. 2014; 99: 257-273; quiz 274-256. PubMed

36. Saravay SM, Kaplowitz M, Kurek J, Zeman D, Pollack S, Novik S, et al.How do delirium and dementia increase length of stay of elderly general medical inpatients? Psychosomatics. 2004; 45: 235-242.

37. Lombard FW, Mathew JP.Neurocognitive dysfunction 
following cardiac surgery. Semin Cardiothorac Vasc Anesth. 2010; 14: 102-110.

38. Boos GL, Soares LF, Oliveira Filho GR.Postoperative cognitive dysfunction: prevalence and associated factors.. Rev Bras Anestesiol. 2005; 55: 517-524.

39. Wang Y, Chen Z, Zhao Y, Shi R, Xu J, Wu A, et al.Epigenetics as a new therapeutic target for postoperative cognitive dysfunction. Med Hypotheses. 2013; 80: 249-251. 40. Medi C, Evered L, Silbert B, Teh A, Halloran K, Morton J, et al . subtlepost- procedural cognitive dysfunction afteratrial fibrillation ablation. J Am Coll Cardiol. 2013; 62:531-539 PubMed

41. Iversen HK, Holm S, Friberg L, Tfelt-Hansen P. In- tracranial hemodynamics during intravenous infusion of glyceryl trinitrate. J Headache Pain. 2008; 9: 177-180 PubMed .

42. Lavine SD, Wang M, Etu JJ, Meyers PM, Joshi S.Augmentation of cerebral blood flow and reversal of endothelin-1-induced vasospasm: a comparison of intracarotid nicardipine and verapamil. Neurosurgery. 2007; 60: 742-748; discussion 748-749.

43. Webb A, Kolenda J, Martin K, Wright W, Samuels O.The effect of intraventricular administration of nicardipine on mean cerebral blood flow velocity measured by transcranial Doppler in the treatment of vasospasm following aneurysmal subarachnoid hemorrhage. Neurocrit Care. 2010; 12: 159-164. 